\title{
Existence and convergence of fixed points for mappings of asymptotically nonexpansive type in uniformly convex W-hyperbolic spaces
}

Jingxin Zhang ${ }^{1 *}$ and Yunan $\mathrm{Cui}^{2}$

\author{
* Correspondence: zhjx_19@yahoo. \\ com.cn \\ 'Department of Mathematics, \\ Harbin Institute of Technology, \\ Harbin 150001, PR China \\ Full list of author information is \\ available at the end of the article
}

\begin{abstract}
Uniformly convex $W$-hyperbolic spaces with monotone modulus of uniform convexity are a natural generalization of both uniformly convexnormed spaces and CAT(0) spaces. In this article, we discuss the existence of fixed points and demiclosed principle for mappings of asymptotically non-expansive type in uniformly convex $W$ hyperbolic spaces with monotone modulus of uniform convexity. We also obtain a $\triangle$-convergence theorem of Krasnoselski-Mann iteration for continuous mappings of asymptotically nonexpansive type in CAT(0) spaces.
\end{abstract}

MSC: 47H09; 47H10; 54E40

Keywords: Asymptotically nonexpansive type, Fixed points $\Delta$-convergence, Uniformly convex $W$-hyperbolic spaces, CAT(0) spaces

\section{Introduction}

In 1974, Kirk [1] introduced the mappings of asymptotically nonexpansive type and proved the existence of fixed points in uniformly convex Banach spaces. In 1993, Bruck et al [2] introduced the notion of mappings which are asymptotically nonexpansive in the intermediate sense (continuous mappings of asymptotically nonexpansive type) and obtained the weak convergence theorems of averaging iteration for mappings of asymptotically nonexpansive in the intermediate sense in uniformly convex Banach space with the Opial property. Since then many authors have studied on the existence and convergence theorems of fixed points for these two classes of mappings in Banach spaces, for example, Xu [3], Kaczor [4,5], Rhoades [6], etc.

In this work, we consider to extend some results to uniformly convex $W$-hyperbolic spaces which are a natural generalization of both uniformly convex normed spaces and CAT(0) spaces. We prove the existence of fixed points and demiclosed principle for mappings of asymptotically nonexpansive type in uniformly convex $W$-hyperbolic spaces with monotone modulus of uniform convexity.

In 1976, Lim [7] introduced a concept of convergence in a general metric space setting which he called " $\Delta$-convergence." In 2008, Kirk and Panyanak [8] specialized Lim's concept to CAT(0) spaces and showed that many Banach space results involving weak convergence have precise analogs in this setting. Since then the notion of $\Delta$-convergence has been widely studied and a number of articles have appeared (e.g., [9-12]).

\section{SpringerOpen ${ }^{\circ}$}

(c) 2011 Zhang and Cui; licensee Springer. This is an Open Access article distributed under the terms of the Creative Commons Attribution License (http://creativecommons.org/licenses/by/2.0), which permits unrestricted use, distribution, and reproduction in any medium, provided the original work is properly cited. 
In this article, we also obtain a $\Delta$-convergence theorem of Krasnoselski-Mann iteration for continuous mappings of asymptotically nonexpansive type in $\mathrm{CAT}(0)$ spaces.

\section{Preliminaries}

First let us start by making some basic definitions. Let $(M, d)$ be a metric space. Asymptotically nonexpansive mappings in Banach spaces were introduced by Geobel and Kirk in 1972 [1].

Definition 2.1. Let $C$ be bounded subset of $M$. A mapping $T: C \rightarrow C$ is called asymptotically nonexpansive if there exists a sequence $\left\{k_{n}\right\}$ of positive real numbers with $k_{n} \rightarrow 1$ as $n \rightarrow \infty$ for which

$$
d\left(T^{n} x, T^{n} y\right) \leq k_{n} d(x, y), \quad \text { for all } x, y \in C .
$$

The mappings of asymptotically nonexpansive type in Banach spaces were defined in 1974 by Kirk [2].

Definition 2.2. Let $C$ be bounded subset of $M$. A mapping $T: C \rightarrow C$ is called asymptotically nonexpansive type if $T$ satisfies

$$
\limsup _{n \rightarrow \infty} \sup _{y \in C}\left(d\left(T^{n} x, T^{n} y\right)-d(x, y)\right) \leq 0
$$

for each $x \in C$, and $T^{N}$ is continuous for some $N \geq 1$.

Obviously, asymptotically nonexpansive mappings are the mappings of asymptotically nonexpansive type.

We work in the setting of hyperbolic space as introduced by Kohlenbach [13]. In order to distinguish them from Gromov hyperbolic spaces [14] or from other notions of "hyperbolic space" which can be found in the literature (e.g., [15-17]), we shall call them $W$-hyperbolic spaces.

A $W$-hyperbolic space $(X, d, W)$ is a metric space $(X, d)$ together with a convexity mapping $W: X \times X \times[0,1] \rightarrow X$ is satisfying

(W1) $d(z, W(x, y, \lambda)) \leq(1-\lambda) d(z, x)+\lambda d(z, y)$;

(W2) $d(W(x, y, \lambda), W(x, y, \tilde{\lambda}))=|\lambda-\tilde{\lambda}| \cdot d(x, y)$;

(W3) $W(x, y, \lambda)=W(y, x, 1-\lambda)$;

(W4) $d(W(x, z, \lambda), W(y, w, \lambda)) \leq(1-\lambda) d(x, y)+\lambda d(z, w)$.

The convexity mapping $W$ was First considered by Takahashi in [18], where a triple $(X, d, W)$ satisfying $(W 1)$ is called a convex metric space. If $(X, d, W)$ satisfying $(W 1)$ (W3), then we get the notion of space of hyperbolic type in the sense of Goebel and Kirk [16]. (W4) was already considered by Itoh [19] under the name "condition III", and it is used by Reich and Shafrir [17] and Kirk [15] to define their notions of hyperbolic space. We refer the readers to [[20], pp. 384-387] for a detailed discussion.

The class of $W$-hyperbolic spaces includes normed spaces and convex subsets thereof, the Hilbert ball [21] as well as CAT(0) spaces in the sense of Gromov (see [14] for a detailed treatment).

If $x, y \in X$ and $\lambda \in[0,1]$, then we use the notation $(1-\lambda) x \oplus \lambda y$ for $W(x, y, \lambda)$. It is easy to see that for any $x, y \in X$ and $\lambda \in[0,1]$,

$$
d(x,(1-\lambda) x \oplus \lambda y)=\lambda d(x, y) \text { and } d(y,(1-\lambda) x \oplus \lambda y)=(1-\lambda) d(x, y) .
$$

As a consequence, $1 x \oplus 0 y=x, 0 x \oplus 1 y=y$ and $(1-\lambda) x \oplus \lambda x=\lambda x \oplus(1-\lambda) x=x$. 
We shall denote by $[x, y]$ the set $\{(1-\lambda) x \oplus \lambda y: \lambda \in[0,1]\}$. Thus, $[x, x]=\{x\}$ and for $x \neq y$, the mapping

$$
\gamma_{x y}:[0, d(x, y)] \rightarrow \mathbb{R}, \quad \gamma_{x y}(\alpha)=\left(1-\frac{\alpha}{d(x, y)}\right) x \oplus \frac{\alpha}{d(x, y)} y
$$

is a geodesic satisfying $\gamma_{x y}([0, d(x, y)])=[x, y]$. That is, any $W$-hyperbolic space is a geodesic space.

A nonempty subset $C \subset X$ is convex if $[x, y] \in C$ for all $x, y \in C$. For any $x \in X, r$ $>0$, the open (closed) ball with center $x$ and radius $r$ is denoted with $U(x, r)$ (respectively $\bar{U}(x, r))$. It is easy to see that open and closed balls are convex. Moreover, using (W4), we get that the closure of a convex subset of a hyperbolic spaces is again convex.

A very important class of $W$-hyperbolic spaces are the CAT(0) spaces. Thus, a $W$ hyperbolic space is a $\mathrm{CAT}(0)$ space if and only if it satisfies the so-called $\mathrm{CN}$-inequality of Bruhat and Tits [22]: For all $x, y, z \in X$,

$$
d\left(z, \frac{1}{2} x \oplus \frac{1}{2} y\right)^{2} \leq \frac{1}{2} d(z, x)^{2}+\frac{1}{2} d(z, y)^{2}-\frac{1}{4} d(x, y)^{2} .
$$

In the following, $(X, d, W)$ is a $W$-hyperbolic space.

Following [18], $(X, d, W)$ is called strictly convex, if for any $x, y \in X$ and $\lambda \in[0,1]$, there exists a unique element $z \in X$ such that

$$
d(z, x)=\lambda d(x, y) \text { and } d(z, y)=(1-\lambda) d(x, y) .
$$

Recently, Leustean [23] defined uniform convexity for $W$-hyperbolic spaces. A $W$ hyperbolic space $(X, d, W)$ is uniformly convex if for any $r>0$ and any $\varepsilon \in(0,2]$ there exists $\theta \in(0,1]$ such that for all $a, x, y \in X$,

$$
\left.\begin{array}{l}
d(x, a) \leq r \\
d(y, a) \leq r \\
d(x, y) \geq \varepsilon r
\end{array}\right\} \Rightarrow d\left(\frac{1}{2} x \oplus \frac{1}{2} y, a\right) \leq(1-\theta) r .
$$

A mapping $\eta:(0, \infty) \times(0,2] \rightarrow(0,1]$ providing such a $\theta:=\eta(r, \varepsilon)$ for given $r>0$ and $\varepsilon \in(0,2]$ is called a modulus of uniform convexity. $\eta$ is called monotone, if it decreases with $r$ (for a fixed $\varepsilon$ ).

Lemma 2.3. [[23], Lemma [7]] Let $(X, d, W)$ be a UCW-hyperbolic space with modulus of uniform convexity $\eta$. For any $r>0, \varepsilon \in(0,2], \lambda \in[0,1]$, and $a, x, y \in X$,

$$
\left.\begin{array}{l}
d(x, a) \leq r \\
d(y, a) \leq r \\
d(x, y) \geq \varepsilon r
\end{array}\right\} \Rightarrow d((1-\lambda) x \oplus \lambda y, a) \leq(1-2 \lambda(1-\lambda) \eta(r, \varepsilon)) r .
$$

We shall refer uniformly convex $W$-hyperbolic spaces as $U C W$-hyperbolic spaces. It turns out that any $U C W$-hyperbolic space is strictly convex (see [23]). It is known that CAT(0) spaces are $U C W$-hyperbolic spaces with modulus of uniform convexity $\eta(r, \varepsilon)$ $=\varepsilon^{2} / 8$ quadratic in $\varepsilon$ (refer to [23] for details). Thus, $U C W$-hyperbolic spaces are a natural generalization of both uniformly convex-normed spaces and CAT(0) spaces. The following proposition can be found in [24]. 
Proposition 2.4. Let $(X, d, W)$ be a complete UCW-hyperbolic space with a monotone modulus of uniform convexity. Then the intersection of any decreasing sequence of nonempty bounded closed convex subsets of $X$ is nonempty.

\section{Fixed point theorem for mappings of asymptotically nonexpansive type}

The First main result of this article is the existence of fixed points for the mappings of asymptotically nonexpansive type in $U C W$-hyperbolic space with a monotone modulus of uniform convexity.

Theorem 3.1. Let $(X, d, W)$ be a complete UCW-hyperbolic space with a monotone modulus of uniform convexity. Let $C$ be a bounded closed nonempty convex subset of $X$. Then, every mapping of asymptotically nonexpansive type $T: C \rightarrow C$ has a fixed point.

PROOF. For any $y \in C$, we consider

$$
B_{y}:=\left\{b \in \mathbb{R}^{+} \text {: there exist } x \in C, k \in \mathbb{N} \text { such that } d\left(T^{i} y, x\right) \leq b \text { for all } i \geq k\right\} .
$$

It is easy to see that $\operatorname{diam}(C) \in B_{y}$, hence $B_{y}$ is nonempty. Let $\beta_{y}:=\inf B_{y}$, then for any $\theta>0$, there exists $b_{\theta} \in B_{y}$ such that $b_{\theta}<\beta_{y^{+}} \theta$, and so there exists $x \in K$ and $k \in$ $\mathbb{N}$ such that

$$
d\left(T^{i} y, x\right) \leq b_{\theta}<\beta_{y}+\theta, \quad \forall i \geq k .
$$

Obviously, $\beta_{y} \geq 0$. We distinguish two cases:

Case 1. $\beta_{y}=0$.

Let $\varepsilon>0$. Applying (3.1) with $\theta=\varepsilon / 2$, we get the existence of $x \in C$ and $k \in \mathbb{N}$ such that for all $m, n \geq k$

$$
d\left(T^{m} y, T^{n} y\right) \leq d\left(T^{m} y, x\right)+d\left(T^{n} y, x\right)<\frac{\varepsilon}{2}+\frac{\varepsilon}{2}=\varepsilon .
$$

Hence, the sequence $\left\{T^{n} y\right\}$ is a Cauchy sequence, and, hence, convergent to some $z \in$ $C$. Let $\zeta>0$ and using the Definition of $T$ choose $M$ so that $i \geq M$ implies

$$
\sup _{x \in C}\left(d\left(T^{i} z, T^{i} x\right)-d(z, x)\right) \leq \frac{1}{3} \zeta .
$$

Given $i \geq M$, since $T^{n}(y) \rightarrow z$, there exists $m>i$ such that $d\left(T^{m} y, z\right) \leq \frac{1}{3} \zeta$ and $d\left(T^{m-i} y, z\right) \leq \frac{1}{3} \zeta$. Thus, if $i \geq M$,

$$
\begin{aligned}
& d\left(z, T^{i} z\right) \leq d\left(z, T^{m} y\right)+d\left(T^{m} y, T^{i} z\right) \\
\leq & d\left(z, T^{m} y\right)+d\left(T^{i} z, T^{i}\left(T^{m-i} \gamma\right)\right)-d\left(z, T^{m-i} \gamma\right)+d\left(z, T^{m-i} \gamma\right) \\
\leq & \frac{1}{3} \zeta+\sup _{x \in C}\left(d\left(T^{i} z, T^{i} x\right)-d(z, x)\right)+\frac{1}{3} \zeta \\
\leq & \zeta .
\end{aligned}
$$

This proves $T^{n} z \rightarrow z$ as $n \rightarrow \infty$. By the continuity of $T^{N}$, we have $T^{N} z=z$. Thus,

$$
T z=T\left(T^{i N} z\right)=T^{i N+1} z \rightarrow z \quad \text { as } i \rightarrow \infty,
$$

and $T z=z$, i.e., $z$ is a fixed point of $T$. 
Case 2. $\beta_{y}>0$. For any $n \geq 1$, we define

$$
C_{n}:=\bigcup_{k \geq 1} \overline{\bar{U}}\left(T^{i}{ }^{i}, \beta_{y}+\frac{1}{n}\right), \quad D_{n}:=\overline{C_{n}} \cap C .
$$

By (3.1) with $\theta=\frac{1}{n}$, there exist $x \in C, k \geq 1$ such that $x \in \bigcap_{i \geq k} \bar{U}\left(T^{i} y, \beta_{y}+\frac{1}{n}\right)$; hence, $D_{n}$ is nonempty. Moreover, $\left\{D_{n}\right\}$ is a decreasing sequence of nonempty-bounded closed convex subsets of $X$, hence, we can apply Proposition 2.4 to derive that

$$
D:=\bigcap_{n \geq 1} D_{n} \neq \emptyset .
$$

For any $x \in D$ and $\theta>0$, take $N \in \mathbb{N}$ such that $\frac{2}{N} \leq \theta$. Since $x \in D$, we have $x \in \overline{C_{N}}$, and so there exists a sequence $\left\{x_{n}^{N}\right\}$ in $C_{N}$ such that $\lim _{n \rightarrow \infty} x_{n}^{N}=x$. Let $P \geq 1$ be such that $d\left(x, x_{n}^{N}\right) \leq \frac{1}{N}$ for all $n \geq P$, and $K \geq 1$ such that $x_{P}^{N} \in \bigcap_{i \geq K} \bar{U}\left(T^{i} y, \beta_{y}+\frac{1}{N}\right)$. It follows that for all $i \geq K$

$$
d\left(T^{i} y, x\right) \leq d\left(T^{i} y, x_{P}^{N}\right)+d\left(x_{P}^{N}, x\right) \leq \beta_{y}+\frac{1}{N}+\frac{1}{N} \leq \beta_{y}+\theta .
$$

In the sequel, we shall prove that any point of $D$ is a fixed point of $T$. Let $x \in D$ and assume by contradiction that $T x \neq x$. Noticing the last part of Case 1 , then $\left\{T^{n} x\right\}$ does not converge to $x$, and so we can find $\varepsilon>0$; for any $k \in \mathbb{N}$, there exists $n \geq k$ such that

$$
d\left(T^{n} x, x\right) \geq \varepsilon .
$$

We can assume that $\varepsilon \in(0,2]$. Then, $\frac{\varepsilon}{\beta_{y}+1} \in(0,2]$ and there exits $\theta_{y} \in(0,1]$ such that

$$
1-\eta\left(\beta_{y}+1, \frac{\varepsilon}{\beta_{y}+1}\right) \leq \frac{\beta_{y}-\theta_{y}}{\beta_{y}+\theta_{y}} .
$$

Applying (3.2) with $\theta=\frac{\theta_{y}}{2}$, there exists $K \in \mathbb{N}$ such that

$$
d\left(T^{i} y, x\right) \leq \beta_{y}+\frac{\theta_{y}}{2}, \quad \forall i \geq K .
$$

By the Definition of $T$, there exists $N$ such that if $m \geq N$, then

$$
\sup _{z \in C}\left(d\left(T^{m} x, T^{m} z\right)-d(x, z)\right) \leq \frac{\theta_{y}}{2} .
$$

Applying (3.3) with $k=N$, we get $N \geq N$ such that

$$
d\left(T^{N} x, x\right) \geq \varepsilon .
$$

Let now $m \in \mathbb{N}$ be such that $m \geq N+K$. Then, by (3.4)-(3.6), we have

$$
\begin{gathered}
d\left(x, T^{m} y\right) \leq \beta_{y}+\frac{\theta_{y}}{2}<\beta_{y}+\theta_{y} ; \\
d\left(T^{N} x, T^{m} y\right)=\left\{d\left(T^{N} x, T^{N}\left(T^{m-N} y\right)\right)-d\left(x, T^{m-N} y\right)\right\}+d\left(x, T^{m-N} \gamma\right) \\
\leq \frac{\theta_{y}}{2}+\beta_{y}+\frac{\theta_{y}}{2}=\beta_{y}+\theta_{y} . \\
d\left(T^{N} x, x\right) \geq \varepsilon=\frac{\varepsilon}{\beta_{y}+\theta_{y}} \cdot\left(\beta_{y}+\theta_{y}\right) \geq \frac{\varepsilon}{\beta_{y}+1} \cdot\left(\beta_{y}+\theta_{y}\right) .
\end{gathered}
$$


Now applying the fact that $X$ is uniformly convex and $\eta$ is monotone, we get that

$$
\begin{aligned}
d\left(\frac{x \oplus T^{N} x}{2}, T^{m} y\right) & \leq\left(1-\eta\left(\beta_{y}+\theta_{y}, \frac{\varepsilon}{\beta_{y}+1}\right)\right)\left(\beta_{y}+\theta_{y}\right) \\
& \leq\left(1-\eta\left(\beta_{y}+1, \frac{\varepsilon}{\beta_{y}+1}\right)\right)\left(\beta_{y}+\theta_{\gamma}\right) \\
& \leq \frac{\beta_{y}-\theta_{y}}{\beta_{y}+\theta_{y}} \cdot\left(\beta_{y}+\theta_{\gamma}\right)=\beta_{\gamma}-\theta_{\gamma} .
\end{aligned}
$$

Thus, there exist $k:=N+K$ and $z:=\frac{x \oplus T^{N} x}{2} \in C$ such that for all $m \geq k, d\left(z, T^{m} y\right) \leq$ $\beta_{y^{-}} \theta_{y}$. This means that $\beta_{y^{-}} \theta_{y} \in B_{y}$, which contradict with $\beta_{y}=\inf B_{y}$. It follows $x$ is a fixed point of $T$.

Since CAT $(0)$ spaces are $U C W$-hyperbolic spaces with a monotone modulus of uniform convexity, we have the following Corollary.

Corollary 3.2. Let $X$ be a complete $C A T(0)$ space and $C$ be a bounded closed nonempty convex subset of $X$. Then every mapping of asymptotically nonexpansive type $T$ : $C \rightarrow C$ has a fixed point.

In the following, we shall prove that a continuous mapping of asymptotically nonexpansive type in $U C W$-hyperbolic space with a monotone modulus of uniform convexity is demiclosed as it was noticed by Cöhde [25] for non-expansive mapping in uniformly convex Banach spaces. Before we state the next result, we need the following notation:

$$
\left\{x_{n}\right\} \rightarrow \omega \text { if and only if } \Phi(\omega)=\inf _{x \in C} \Phi(x),
$$

where $C$ is a closed convex subset which contains the bounded sequence $\left\{x_{n}\right\}$ and $\Phi$ $(x)=\lim \sup _{n \rightarrow \infty} d\left(x_{n}, x\right)$.

Theorem 3.3. Let $(X, d, W)$ be a complete UCW-hyperbolic space with a monotone modulus of uniform convexity and $C$ be a bounded closed nonempty convex subset of $X$. Let $T: C \rightarrow C$ be a continuous mapping of asymptotically nonexpansive type. Let $\left\{x_{n}\right\}$ $\subset C$ be an approximate fixed point sequence, i.e., $\lim _{n \rightarrow \infty} d\left(x_{n}, T x_{n}\right)=0$, and $\left\{x_{n}\right\} \rightarrow \omega$.

Then, we have $T(\omega)=\omega$.

PROOF. We denote

$$
c_{n}=\max \left\{0, \sup _{x, y \in C}\left(d\left(T^{n} x, T^{n} y\right)-d(x, y)\right)\right\} .
$$

Since $\left\{x_{n}\right\}$ is an approximate fixed point sequence, then we have

$$
\Phi(x)=\limsup _{n \rightarrow \infty} d\left(T^{m} x_{n}, x\right)
$$

for any $m \geq 1$. Hence, for each $x \in C$

$$
\Phi\left(T^{m} x\right)=\limsup _{n \rightarrow \infty} d\left(T^{m} x_{n}, T^{m} x\right) \leq \Phi(x)+c_{m}
$$

In particular, noticing that $\lim \sup _{m \rightarrow \infty} c_{m}=0$, we have

$$
\lim _{m \rightarrow \infty} \Phi\left(T^{m} \omega\right) \leq \Phi(\omega) .
$$

Assume by contradiction that $T \omega \neq \omega$. Then, $\left\{T^{m} \omega\right\}$ does not converge to $\omega$, so we can find $\varepsilon_{0}>0$, for any $k \in \mathbb{N}$, there exists $m \geq k$ such that $d\left(T^{m} \omega, \omega\right) \geq \varepsilon_{0}$. We can assume $\varepsilon_{0} \in(0,2]$. Then, $\frac{\varepsilon_{0}}{\Phi(\omega)+1} \in(0,2]$ and there exists $\theta \in(0,1]$ such that 


$$
1-\eta\left(\Phi(\omega)+1, \frac{\varepsilon_{0}}{\Phi(\omega)+1}\right) \leq \frac{\Phi(\omega)-\theta}{\Phi(\omega)+\theta}
$$

By the definition of $\Phi$ and (3.7), for the above $\theta$, there exists $N, M \in \mathbb{N}$, such that

$$
\begin{gathered}
d\left(\omega, x_{n}\right) \leq \Phi(\omega)+\theta, \quad \forall n \geq N \\
d\left(T^{m} \omega, x_{n}\right) \leq \Phi(\omega)+\theta, \quad \forall n \geq N, \quad \forall m \geq M .
\end{gathered}
$$

For $M$, there exists $m \geq M$ such that

$$
d\left(T^{m} \omega, \omega\right) \geq \varepsilon_{0}=\frac{\varepsilon_{0}}{\Phi(\omega)+\theta} \cdot(\Phi(\omega)+\theta) \geq \frac{\varepsilon_{0}}{\Phi(\omega)+1} \cdot(\Phi(\omega)+\theta) .
$$

Since $X$ is uniformly convex and $\eta$ is monotone, applying (3.8) we have

$$
\begin{aligned}
d\left(\frac{\omega \oplus T^{m} \omega}{2}, x_{n}\right) & \leq\left(1-\eta\left(\Phi(\omega)+\theta, \frac{\varepsilon_{0}}{\Phi(\omega)+1}\right)\right) \cdot(\Phi(\omega)+\theta) \\
& \leq \frac{\Phi(\omega)-\theta}{\Phi(\omega)+\theta} \cdot(\Phi(\omega)+\theta) \\
& =\Phi(\omega)-\theta
\end{aligned}
$$

Since $z:=\frac{\omega \oplus T^{m} \omega}{2} \in C$ and $z \neq \omega$, we have got a contradiction with $\Phi(\omega)=\inf _{x \in C}$ $\Phi(x)$. It follows that $T \omega=\omega$.

Corollary 3.4. Let $X$ be a complete $C A T(0)$ metric space and $C$ be a bounded closed nonempty convex subset of $X$. Let $T: C \rightarrow C$ be a continuous mapping of asymptotically nonexpansive type. Let $\left\{x_{n}\right\} \subset C$ be an approximate fixed point sequence and $\left\{x_{n}\right\} \rightarrow \omega$. Then, we have $T \omega=\omega$.

\section{4. $\Delta$-convergence theorems for continuous mappings of asymptotically nonexpansive type in CAT(0) spaces}

Let $(X, d)$ be a metric space, $\left\{x_{n}\right\}$ be a bounded sequence in $X$ and $C \subset X$ be a nonempty subset of $X$. The asymptotic radius of $\left\{x_{n}\right\}$ with respect to $C$ is defined by

$$
r\left(C,\left\{x_{n}\right\}\right)=\inf \left\{\limsup _{n \rightarrow \infty} d\left(x, x_{n}\right): x \in C\right\} .
$$

The asymptotic radius of $\left\{x_{n}\right\}$, denoted by $r\left(\left\{x_{n}\right\}\right)$, is the asymptotic radius of $\left\{x_{n}\right\}$ with respect to $X$. The asymptotic center of $\left\{x_{n}\right\}$ with respect to $C$ is defined by

$$
A\left(C,\left\{x_{n}\right\}\right)=\left\{z \in C: \limsup _{n \rightarrow \infty} d\left(z, x_{n}\right)=r\left(\left\{C, x_{n}\right\}\right)\right\} .
$$

When $C=X$, we call the asymptotic center of $\left\{x_{n}\right\}$ and use the notation $A\left(\left\{x_{n}\right\}\right)$ for $A$ $\left(C,\left\{x_{n}\right\}\right)$.

The following proposition was proved in [26].

Proposition 4.1. If $\left\{x_{n}\right\}$ is a bounded sequence in a complete CAT(O) space $X$ and if $C$ is a closed convex subset of $X$, then there exists a unique point $u \in C$ such that

$$
r\left(u,\left\{x_{n}\right\}\right)=\inf _{x \in C} r\left(x,\left\{x_{n}\right\}\right)
$$

The above immediately yields the following proposition.

Proposition 4.2. Let $\left\{x_{n}\right\}, C$ and $X$ be as in Proposition 4.1. Then, $A\left(\left\{x_{n}\right\}\right)$ and $A(C$, $\left.\left\{x_{n}\right\}\right)$ are singletons. 
The following lemma can be found in [27].

Lemma 4.3. If $C$ is a closed convex subset of $X$ and $\left\{x_{n}\right\}$ is a bounded sequence in $C$, then the asymptotic center of $\left\{x_{n}\right\}$ is in $C$.

Definition 4.4. $[7,8]$ A sequence $\left\{x_{n}\right\}$ in $X$ is said to $\Delta$-converge to $x \in X$ if $x$ is the unique asymptotic center of $\left\{u_{n}\right\}$ for every subsequence $\left\{u_{n}\right\}$ of $\left\{x_{n}\right\}$. In this case, we write $\Delta-\lim _{n \rightarrow \infty} x_{n}=x$ and call $x$ the $\Delta$-limit of $\left\{x_{n}\right\}$.

Lemma 4.5. (see [8]) Every bounded sequence in a complete CAT(0) space always has a $\Delta$-convergent subsequence.

There exists a connection between " $\rightarrow$ " and $\Delta$-convergence.

Proposition 4.6. (see [28]) Let $\left\{x_{n}\right\}$ be a bounded sequence in a CAT(0) space $X$ and let $C$ be a closed convex subset of $X$ which contains $\left\{x_{n}\right\}$. Then,

(1) $\Delta-\lim _{n \rightarrow \infty} x_{n}=x$ implies $\left\{x_{n}\right\}-x$;

(2) if $\left\{x_{n}\right\}$ is regular, then $\left\{x_{n}\right\}-x$ implies $\Delta-\lim _{n \rightarrow \infty} x_{n}=x$.

The following concept for Banach spaces is due to Schu [29]. Let $C$ be a nonempty closed subset of a CAT(0) space $X$ and let $T: C \rightarrow C$ be an asymptotically nonexpansive mapping. The Krasnoselski-Mann iteration starting from $x_{1} \in C$ is defined by

$$
x_{n+1}=\alpha_{n} T^{n}\left(x_{n}\right) \oplus\left(1-\alpha_{n}\right) x_{n}, \quad n \geq 1,
$$

where $\left\{\alpha_{n}\right\}$ is a sequence in $[0,1]$. In the sequel, we consider the convergence of the above iteration for continuous mappings of asymptotically nonexpansive type. The following Lemma (also see [3]) is trivial.

Lemma 4.7. Suppose $\left\{r_{k}\right\}$ is a bounded sequence of real numbers and $\left\{a_{k, m}\right\}$ is a doubly indexed sequence of real numbers which satisfy

$$
\limsup _{k \rightarrow \infty} \limsup _{m \rightarrow \infty} a_{k, m} \leq 0, \quad r_{k+m} \leq r_{k}+a_{k, m} \text { for each } k, m \geq 1 .
$$

Then $\left\{r_{k}\right\}$ converges to an $r \in R$; if $a_{k, m}$ can be taken to be independent of $k$, i.e. $a_{k, m} \equiv$ $a_{m}$, then $r \leq r_{k}$ for each $k$.

Lemma 4.8. Let $(X, d, W)$ be a complete $U C W$-hyperbolic space with a monotone modulus of uniform convexity and $C$ be a bounded closed nonempty convex subset of $X$. Let $T: C \rightarrow C$ be a continuous mapping of asymptotically nonexpansive type. Put

$$
c_{n}=\max \left\{0, \sup _{x, y \in C}\left(d\left(T^{n} x, T^{n} y\right)-d(x, y)\right)\right\} .
$$

If $\sum_{n=1}^{\infty} c_{n}<\infty$ and $\left\{\alpha_{n}\right\}$ is a sequence in $[a, b]$ for some $a, b \in(0,1)$. Suppose that $x_{1}$ $\in C$ and $\left\{x_{n}\right\}$ generated by (4.1) for $n \geq 1$, Then $\lim _{n \rightarrow \infty} d\left(x_{n}, p\right)$ exists for each $p \in$ Fix (T).

PROOF. Let $p \in \operatorname{Fix}(T)$. From (4.1), we have

$$
\begin{aligned}
d\left(x_{n+1}, p\right) & =d\left(\alpha_{n} T^{n} x_{n} \oplus\left(1-\alpha_{n}\right) x_{n}, p\right) \\
& \leq \alpha_{n} d\left(T^{n} x_{n}, p\right)+\left(1-\alpha_{n}\right) d\left(x_{n}, p\right) \text { by (W1) } \\
& =\alpha_{n} d\left(T^{n} x_{n}, T^{n} p\right)+\left(1-\alpha_{n}\right) d\left(x_{n}, p\right) \\
& \leq \alpha_{n}\left(d\left(x_{n}, p\right)+c_{n}\right)+\left(1-\alpha_{n}\right) d\left(x_{n}, p\right) \\
& \leq d\left(x_{n}, p\right)+c_{n},
\end{aligned}
$$


and hence that

$$
d\left(x_{k+m}, p\right) \leq d\left(x_{k}, p\right)+\sum_{n=k}^{k+m-1} c_{n} .
$$

Applying Lemma 4.7 with $r_{k}=d\left(x_{k}, p\right)$ and $a_{k, m}=\sum_{n=k}^{k+m-1} c_{n}$, we get that $\lim _{n \rightarrow \infty} d\left(x_{n}\right.$, p) exists.

Lemma 4.9. Let $(X, d, W)$ be a complete $U C W$-hyperbolic space with a monotone modulus of uniform convexity and $C$ be a bounded closed nonempty convex subset of $X$. Let $T: C \rightarrow C$ be a continuous mapping of asymptotically nonexpansive type. Put

$$
c_{n}=\max \left\{0, \sup _{x, y \in C}\left(d\left(T^{n} x, T^{n} y\right)-d(x, y)\right)\right\} .
$$

If $\sum_{n=1}^{\infty} c_{n}<\infty$ and $\left\{\alpha_{n}\right\}$ is a sequence in $[a, b]$ for some $a, b \in(0,1)$. Suppose that $x_{1}$ $\in C$ and $\left\{x_{n}\right\}$ generated by (4.1) for $n \geq 1$. Then,

$$
\lim _{n \rightarrow \infty} d\left(x_{n}, T x_{n}\right)=0 .
$$

PROOF. It follows from Theorem 3.1, $T$ has at least one fixed point $p$ in $C$. In view of Lemma 4.8 we can let $\lim _{n \rightarrow \infty} d\left(x_{n}, p\right)=r$ for some $r$ in $\mathbb{R}$.

If $r=0$, then we immediately obtain

$$
d\left(x_{n}, T x_{n}\right) \leq d\left(x_{n}, p\right)+d\left(T x_{n}, p\right)=d\left(x_{n}, p\right)+d\left(T x_{n}, T p\right),
$$

and hence by the uniform continuity of $T$, we have $\lim _{n \rightarrow \infty} d\left(x_{n}, T x_{n}\right)=0$.

If $r>0$, then we shall prove that

$$
\lim _{n \rightarrow \infty} d\left(T^{n} x_{n}, p\right)=\lim _{n \rightarrow \infty} d\left(\alpha_{n} T^{n} x_{n} \oplus\left(1-\alpha_{n}\right) x_{n}, p\right)=r
$$

by showing that for any increasing sequence $\left\{n_{i}\right\}$ of positive integers for which the limits in (4.2) exist, and it follows that the limit is $r$. Without loss of generality we may assume that the corresponding subsequence $\left\{\alpha_{n_{i}}\right\}$ converges to some $\alpha$; we shall have $\alpha>0$ because $\left\{\alpha_{n_{i}}\right\}$ is assumed to be bounded away from 0 . Thus, we have

$$
\begin{aligned}
r=\lim _{n \rightarrow \infty} d\left(x_{n}, p\right) & =\lim _{i \rightarrow \infty} d\left(x_{n_{i}+1}, p\right)=\lim _{i \rightarrow \infty} d\left(\alpha_{n_{i}} T^{n_{i}} x_{n_{i}} \oplus\left(1-\alpha_{n_{i}}\right) x_{n_{i}}, p\right) \\
& \leq \lim _{i \rightarrow \infty}\left(\alpha_{n_{i}} d\left(T^{n_{i}} x_{n^{\prime}}, p\right)+\left(1-\alpha_{n_{i}}\right) d\left(x_{n_{i^{\prime}}}, p\right)\right) \quad \text { by (W1) } \\
& \leq \alpha \limsup _{i \rightarrow \infty} d\left(T^{n_{i}} x_{n_{i}}, p\right)+(1-\alpha) r \\
& \leq \alpha \limsup _{i \rightarrow \infty}\left(d\left(x_{n^{\prime}}, p\right)+c_{n_{i}}\right)+(1-\alpha) r \\
& \leq \alpha \limsup _{i \rightarrow \infty} d\left(x_{n_{i}}, p\right)+(1-\alpha) r=r .
\end{aligned}
$$

It follows that (4.2) holds.

In the sequel, we shall prove $\lim _{n \rightarrow \infty} d\left(T^{n} x_{n}, x_{n}\right)=0$. Assume by contradiction that $\left\{T^{n} x_{n}\right\}$ does not converge to $x_{n}$, and so we can find $\varepsilon>0$ and $\left\{n_{k}\right\} \subset \mathbb{N}$ such that

$$
d\left(T^{n_{k}} x_{n_{k}}, x_{n_{k}}\right) \geq \varepsilon .
$$

We can assume that $\varepsilon \in(0,2]$. Then, $\frac{\varepsilon}{r+1} \in(0,2]$. Since $\left\{\alpha_{n}\right\}$ is a sequence in $[a, b]$ for some $a, b \in(0,1)$, we may assume that $\lim _{k \rightarrow \infty} \min \left\{\alpha_{n_{k}},\left(1-\alpha_{n_{k}}\right)\right\}$ exists, denoted 
by $\alpha_{0}$, then $\alpha_{0}>0$. Choose $\theta \in(0,1]$ such that

$$
1-\alpha_{0} \eta\left(r+1, \frac{\varepsilon}{r+1}\right) \leq \frac{r-\theta}{r+\theta} .
$$

For the above $\theta>0$, there exists $N \in \mathbb{N}$ such that

$$
d\left(x_{n_{k}}, p\right) \leq r+\theta \text { and } d\left(T^{n_{k}} x_{n_{k}}, p\right) \leq r+\theta, \quad \forall k \geq N .
$$

For $k \geq N$, we also have that

$$
d\left(T^{n_{k}} x_{n_{k}}, x_{n_{k}}\right) \geq \varepsilon=\frac{\varepsilon}{r+\theta} \cdot(r+\theta) \geq \frac{\varepsilon}{r+1} \cdot(r+\theta) .
$$

Now applying the fact that $X$ is uniformly convex and $\eta$ is monotone, by Lemma 2.3, we get that

$$
\begin{aligned}
& d\left(\alpha_{n_{k}} T^{n_{k}} x_{n_{k}} \oplus\left(1-\alpha_{n_{k}}\right) x_{n_{n^{\prime}}} p\right) \\
\leq & \left(1-2 \alpha_{n_{k}}\left(1-\alpha_{n_{k}}\right) \eta\left(r+\theta, \frac{\varepsilon}{r+1}\right)\right)(r+\theta) \\
\leq & \left(1-2 \alpha_{n_{k}}\left(1-\alpha_{n_{k}}\right) \eta\left(r+1, \frac{\varepsilon}{r+1}\right)\right)(r+\theta) \\
\leq & \left(1-2 \min \left\{\alpha_{n_{k^{\prime}}}\left(1-\alpha_{n_{k}}\right)\right\} \eta\left(r+1, \frac{\varepsilon}{r+1}\right)\right)(r+\theta) .
\end{aligned}
$$

Let $k \rightarrow \infty$, we obtain that

$$
r \leq\left(1-2 \alpha_{0}\right) \eta\left(r+1, \frac{\varepsilon}{r+1}\right)(r+\theta) \leq \frac{r-\theta}{r+\theta} \cdot(r+\theta)=r-\theta .
$$

Hence, we get a contradiction, and therefore

$$
\lim _{n \rightarrow \infty} d\left(T^{n} x_{n}, x_{n}\right)=0 .
$$

This is equivalent to

$$
\lim _{n \rightarrow \infty} d\left(x_{n}, x_{n+1}\right)=0 .
$$

Thus, we have

$$
\begin{aligned}
d\left(x_{n}, T x_{n}\right) \leq & d\left(x_{n}, x_{n+1}\right)+d\left(x_{n+1}, T^{n+1} x_{n+1}\right) \\
& +d\left(T^{n+1} x_{n+1}, T^{n+1} x_{n}\right)+d\left(T\left(T^{n} x_{n}\right), T x_{n}\right) \\
\leq & d\left(x_{n}, x_{n+1}\right)+d\left(x_{n+1}, T^{n+1} x_{n+1}\right) \\
& +d\left(x_{n+1}, x_{n}\right)+c_{n+1}+d\left(T\left(T^{n} x_{n}\right), T x_{n}\right) .
\end{aligned}
$$

By (4.3), (4.4) and the uniform continuity of $T$, we conclude that $d\left(x_{n}, T x_{n}\right) \rightarrow 0$ as $n$ $\rightarrow \infty$.

The following lemma can be found in [9].

Lemma 4.10. If $\left\{x_{n}\right\}$ is a bounded sequence in a CAT(0) space $X$ with $A\left(\left\{x_{n}\right\}\right)=\{x\}$ and $\left\{u_{n}\right\}$ is a subsequence of $\left\{u_{n}\right\}$ with $A\left(\left\{u_{n}\right\}\right)=\{u\}$ and the sequence $\left\{d\left(x_{n}, u\right)\right\}$ converges, then $x=u$.

Lemma 4.11. Let $X$ be a complete $C A T(0)$ space. Let $C$ be a closed convex subset of $X$, and let $T: C \rightarrow C$ be a continuous mapping of asymptotically nonexpansive type. Suppose that $\left\{x_{n}\right\}$ is a bounded sequence in $C$ such that $\lim _{n \rightarrow \infty} d\left(x_{n}, T x_{n}\right)=0$ and $d\left(x_{n}\right.$, $p$ ) converges for each $p \in \operatorname{Fix}(T)$, then $\omega_{w}\left(x_{n}\right) \subset \operatorname{Fix}(T)$. Here $\omega_{w}\left(x_{n}\right)=\bigcup A\left(\left\{u_{n}\right\}\right)$, 
where the union is taken over all subsequences $\left\{u_{n}\right\}$ of $\left\{x_{n}\right\}$. Moreover, $\omega_{w}\left(x_{n}\right)$ consists of exactly one point.

PROOF. Let $u \in \omega_{w}\left(x_{n}\right)$, then there exists a subsequence $\left\{u_{n}\right\}$ of $\left\{x_{n}\right\}$ such that $A$ $\left(\left\{u_{n}\right\}\right)=\{u\}$. Since $\left\{u_{n}\right\}$ is bounded sequence, by Lemma 4.5 and 4.3 there exists a subsequence $\left\{v_{n}\right\}$ of $\left\{u_{n}\right\}$ such that $\Delta-\lim _{n \rightarrow \infty} v_{n}=v \in C$. By Corollary 3.4, we have $v \in$ Fix $(T)$. By Lemma 4.10, $u=v$. This shows that $\omega_{w}\left(x_{n}\right) \subset \operatorname{Fix}(T)$. Next, we show that $\omega_{w}\left(x_{n}\right)$ consists of exactly one point. Let $\left\{u_{n}\right\}$ be a subsequence of $\left\{x_{n}\right\}$ with $A\left(\left\{u_{n}\right\}\right)=$ $u$, and let $A\left(\left\{x_{n}\right\}\right)=x$. Since $u \in \omega_{w}\left(x_{n}\right) \subset F i x(T),\left\{d\left(x_{n}, u\right)\right\}$ converges. By Lemma 4.10, $x=u$. This completes the proof.

Theorem 4.12. Let $X$ be a complete $C A T(0)$ space. Let $C$ be a bounded closed convex subset of $X$, and let $T: C \rightarrow C$ be a continuous mapping of asymptotically nonexpansive type with $\sum_{n=1}^{\infty} c_{n}<\infty$, Where

$$
c_{n}=\max \left\{0, \sup _{x, y \in C}\left(d\left(T^{n} x, T^{n} y\right)-d(x, y)\right)\right\} .
$$

Suppose that $x_{1} \in C$ and $\left\{\alpha_{n}\right\}$ is a sequence in $[a, b]$ for some $a, b \in(0,1)$. Then, the sequence $\left\{x_{n}\right\}$ given by (4.1) $\Delta$-converges to a fixed point of $T$.

PROOF. It follows from Corollary 3.2 that $\operatorname{Fix}(T)$ is nonempty. Since CAT(0) spaces are $U C W$-hyperbolic spaces with a monotone modulus of uniform convexity, by Lemma 4.8, $\left\{d\left(x_{n}, p\right)\right\}$ is convergent for each $p \in \operatorname{Fix}(T)$. By Lemma 4.9, we have $\lim _{n \rightarrow \infty} d\left(x_{n}, T x_{n}\right)=0$. By Lemma 4.11, $\omega_{w}\left(x_{n}\right)$ consists of exactly one point and is contained in $\operatorname{Fix}(T)$. This shows that $\left\{x_{n}\right\} \Delta$-converges to an element of Fix $(T)$.

\section{Acknowledgements}

The authors would like to thank the anonymous referee for some valuable comments and useful suggestions. Supported by Academic Leaders Fund of Harbin University of Science and Technology and Young Scientist Fund of Harbin University of Science and Technology under grant 2009 YF029.

\section{Author details}

'Department of Mathematics, Harbin Institute of Technology, Harbin 150001, PR China 2Department of Mathematics, Harbin University of Science and Technology, Harbin, 150080, PR China

\section{Authors' contributions}

YC contributed the ideas and gave some valuable suggestions. JZ participated in the sequence alignment and drafted the manuscript. All authors read and approved the final manuscript.

\section{Competing interests}

The authors declare that they have no competing interests.

Received: 10 April 2011 Accepted: 19 August 2011 Published: 19 August 2011

\section{References}

1. Geobel, K, Kirk, WA: A fixed point theorem for asymptotically nonexpansive mappings. Proc Am Math Soc. 35, 171-174 (1972). doi:10.1090/S0002-9939-1972-0298500-3

2. Kirk, WA: 'Fixed point theorems for non-Lipschitzian mappings of asymptotically nonexpansive types. Israel J Math. 17, 339-346 (1974). doi:10.1007/BF02757136

3. Bruck, RE, Kuczumow, T, Reich, S: 'Convergence of iterates of asymptotically nonexpansive mappings in Banach spaces with the uniform Opial property. Colloqium Math. LXV. 169-179 (1993)

4. Hong-Kun, $X$ : Existence and convergence for fixed points of mappings of asymptotically nonexpansive type. Nonlinear Anal Theory Methods Appl. 16(12), 1139-1146 (1991). doi:10.1016/0362-546X(91)90201-B

5. Kaczor, W, Walczuk, J: 'A mean ergodic theorem for mappings which are asymptotically nonexpansive in the intermediate sense. Nonlinear Anal: Theory Methods Appl. 47, 2731-2742 (2001). doi:10.1016/S0362-546X(01)00392-3

6. Rhoades, BE, Soltuz, SM: The equivalence between the convergences of Ishikawa and Mann iterations for an asymptotically nonexpansive in the intermediate sense and strongly successively pseudocontractive maps. J Math Analysis Appl. 289, 266-278 (2004). doi:10.1016/j.jmaa.2003.09.057

7. Lim, TC: Remarks on some fixed point theorems. Proc Am Math Soc. 60, 179-182 (1976). doi:10.1090/S0002-9939-19760423139-X

8. Kirk, WA, Panyanak, B: A concept of convergence in geodesic spaces. Nonlinear Anal Theory Methods Appl. 68, 3689-3696 (2008). doi:10.1016/j.na.2007.04.011 
9. Dhompongsa, S, Payanak, B: On $\Delta$-convergence theorems in CAT(0) spaces. Comput Math Appl. 56, 2572-2579 (2008). doi:10.1016/j.camwa.2008.05.036

10. Laokul, T, Panyanak, B: Approximating fixed points of nonexpansive mappings in CAT(0) spaces. Int J Math Anal. 3(27), 1305-1315 (2009)

11. Laowang, W, Panyanak, B: Strong and $\triangle$ convergence theorems for multivalued mappings in CAT(0) spaces. J Inequal Appl. 2009, 16 (2009)

12. Nanjaras, B, Panyanak, B, Phuengrattana, W: Fixed point theorems and convergence theorems for Suzuki-generalized nonexpansive mappings in CAT(0) spaces. Nonlinear Anal: Hybird Syst. 4(1), $25-31$ (2010). doi:10.1016/..nahs.2009.07.003

13. Kohlenbach, U: Some logical metaheorems with applications in functional analysis. Trans Am Math Soc. 357(1), 89-128 (2005). doi:10.1090/50002-9947-04-03515-9

14. Bridson, M, Haeiger, A: Metric spaces of non-positive curvature, Grundlehren der Mathematischen Wissenschaften. Springer, Berlin319 (1999)

15. Kirk, WA: Krasnosel'skii iteration process in hyperbolic spaces. Nume Funct Anal Optim. 4, 371-381 (1982). doi:10.1080/ 01630568208816123

16. Goebel, K, Kirk, WA: Iteration processes for nonexpansive mappings. In: Singh SP, Thomeier S, Watson B (eds.) Topological methods in nonlinear functional analysis (Toronto, 1982), Contemporary Mathematics, vol. 21, pp. 115-123. American Mathematical Society, Providence, RI (1983)

17. Reich, S, Shafrir, I: Nonexpansive iterations in hyperbolic spaces. Nonlinear Anal: Theory, Methods Appl. 15, 537-338 (1990). doi:10.1016/0362-546X(90)90058-0

18. Takahashi, W: A convexity in metric space and nonexpansive mappings. Kodai Math Semin Rep. 22(2), 142-149 (1970). doi:10.2996/kmj/1138846111

19. Itoh, S: Some fixed point theorems in metric spaces. Fundam Math. 102, 109-117 (1979)

20. Kohlenbach, U, Leustean, L: Applied Proof Theory: Proof Interpretations and Their Use in Mathematics. Springer Monographs in Mathematics. Springer, Berlin (2008)

21. Goebel, K, Reich, S: Uniform convexity, hyperbolic geometry, and non-expansive mappings. Monographs Textbooks in Pure and Applied Mathematices. Marcel Dekker, Inc., New York (1984)

22. Bruhat, M, Tits, J: Groupes réducifs sur un corps local. Institut des Hautes Études Scientifiques. pp. 5-251. Publications Mathématiques41, (1972)

23. Leustean, L: A quadratic rate of asymptotic regularity for CAT(0)-spaces. J Math Anal Appl. 325, 386-399 (2007). doi:10.1016/j.jmaa.2006.01.081

24. Kohlenbach, U, Leustean, L: Asymptotically nonexpansive mappings in uniformly convex hyperbolic spaces. J Eur Math Soc. (in press)

25. Göhde, D: Zum Prinzip der kontraktiven Abbidung. Mathematische Nachrichten. 30, 251-258 (1965). doi:10.1002/ mana.19650300312

26. Dhompongsa, S, Kirk, WA, Sims, B: Fixed points of uniformly Lip-schitzian mappings. Nonlinear Anal: Theory Methods Appl. 65(4), 762-772 (2006). doi:10.1016/j.na.2005.09.044

27. Dhompongsa, S, Kirk, WA, Panyanak, B: Nonexpansive set-valued mappings in metric and Banach spaces. J Nonlinear Convex Anal. 8(1), 35-45 (2007)

28. Nanjaras, B, Panyanak, B: Demiclosed principle for asymptotically nonexpansive mappings in CAT(0) spaces. Fixed Point Theory Appl2010. (Article ID 268780)

29. Schu, J: Iterative construction of fixed points of asymptotically nonexpansive mappings. J Math Anal Appl. 158, 407-413 (1991). doi:10.1016/0022-247X(91)90245-U

doi:10.1186/1687-1812-2011-39

Cite this article as: Zhang and Cui: Existence and convergence of fixed points for mappings of asymptotically nonexpansive type in uniformly convex W-hyperbolic spaces. Fixed Point Theory and Applications 2011 2011:39.

\section{Submit your manuscript to a SpringerOpen ${ }^{\odot}$ journal and benefit from:}

- Convenient online submission

- Rigorous peer review

- Immediate publication on acceptance

- Open access: articles freely available online

- High visibility within the field

- Retaining the copyright to your article

Submit your next manuscript at $\gg$ springeropen.com 